\title{
Academic Dishonesty in Assessment Settings: An Overview of Distance Learning Institution
}

\author{
Mmankoko Ziphorah Ramorola
}

Department of Science and Technology Education, University of South Africa (UNISA)

PO Box 392 Pretoria 0003

\section{Doi:10.5901/mjss.2014.v5n20p1623}

\section{Abstract}

Academic dishonesty in summative assessment is a global problem. Education institutions continue to develop new ways to prevent dishonest behaviours such as cheating from happening. These ways include adopting academic honesty policies, instituted academic integrity tutorial completion prerequisites for registration, and acquired plagiarism software detection tools, while at the same time cheats come up with even better ways to cheat. While there has been significant research on the subject of academic dishonesty, the problem still persists especially in distance learning institutions of higher education. The reasons for students' engagement in dishonest behaviour are not well known. If these reasons can be well understood, academic dishonesty in summative assessment will be minimised. Informed by the theory of planned behaviour, this paper presents an overview of distance education students' reasons for engaging in dishonesty behaviour during the examinations. The study followed a qualitative case study design to collect and analyse data. The findings revealed reasons such as: lack of time for exam preparations; family bereavement, family responsibility; and forgetfulness. The study suggests recommendations for improvement and further research; and concludes that to maintain the integrity of the institution, the Disciplinary Code for Students has to be respected and implemented by all the stakeholders of the University.

Keywords: cheating, summative assessment, distance learning, higher education institutions, theory of planned behaviour

\section{Introduction}

Cheating in summative assessment has always been a serious concern in higher educational institutions of distance learning. Cheating is epidemic across most college campuses and the majority of students have engaged in it at some point (Lambert and Hogan, 2004). For an example, Norton, Tilley, Newstead and Franklyn-Stokes (2001) appraisal of 267 psychology students at four British institutions of higher education determined that at least half of all college students engaged in academic dishonesty in assessment settings. A study on situational and personal causes of student cheating (Rettinger and Kramer, 2008) highlights that $73,4 \%$ reported engaging in at least one of the cheating behaviour, and $37,7 \%$ reported serious cheating on an examination. Fifty percent of the study participants reported using unauthorised information on an exam paper. Other studies (see Wotring and Bol, 2005; Teixeira, 2008; Trost, 2009; Jones, 2011) confirmed that students cheat at higher education institutions such as community colleges in the United States and universities in Sweden, Bucharest, Spain and Portugal. The phenomenon of cheating in distance learning institutions of higher education, does not exclude South Africa.

The students under investigation have registered for an undergraduate programme, the Advanced Certificate in Education (ACE) in one of the distance learning institutions in South Africa. It is evident in the study that students engaged themselves in academic dishonesty during examination. The reasons for this practice are not well known. Although the causes of increased cheating are unknown, some speculate it is due to more pressure for success (Callahan, 2004). Numerous studies have examined the frequency of academic dishonesty in online settings (see Kennedy et al., 2000; McEwen et al., 2009; Kietz-Uhler and Hurn, 2011). Relatively few studies have examined the reasons of distance learning students' engagement in cheating (see Rettinger and Kramer, 2009; Robinson, 2013).

This paper presents an overview of students' reasons for engaging in cheating behaviour during examinations. According to the theory of planned behaviour (TpB) human behaviour is guided by three kinds of considerations (Ajzen, 2006): beliefs about the likely consequences of the behaviour (behavioural beliefs), beliefs about the normative expectations of others (normative beliefs), and beliefs about the presence of factors that may facilitate or impede performance of the behaviour (control beliefs). Behavioural beliefs produce a favourable or unfavourable attitude toward the behaviour, normative beliefs result in perceived social pressure or subjective norm, and control beliefs give rise to perceived behavioural control. In combination attitude toward the behaviour, subjective norm, and perception of 
behavioural control lead to the formation of a behavioural intention. The more favourable the attitude and subjective norm, and the greater the perceived control, the stronger should be the person's intention to perform the behaviour in question. Given a sufficient degree of actual control over the behaviour, people are expected to carry out their intentions when the opportunity arises.

There is a growing literature dealing with online education and academic misconduct. Little research attention has focused on the reasons of cheating and summative assessment in face-to-face distance learning courses, especially in South Africa. What follows is a summation of the literature on cheating in general, cheating and distance learning, and cheating in the South African context.

\section{Literature Review}

\subsection{Cheating}

Generally, cheating is considered to be the act of getting something by dishonesty or deception. At university, it is considered to be synonymous with academic dishonesty (Trost, 2009). Academic dishonesty is defined as "a transgression against academic integrity which entails taking an unfair advantage that results in a misrepresentation of a student's ability and grasp of knowledge" (King, Gugetter, and Piotrowski, 2009:4). Examples of academic dishonesty include the unauthorised use of material on an assignment or an examination, looking at another student's examination, and assisting another student to gain an unfair advantage relative to his or her peers (Robinson, 2013). In this study the practice of cheating followed an example whereby unauthorised materials were used in the examination. For the purpose of this study, the terms academic dishonesty, academic misconduct and cheating are used interchangeably.

According to Nelson (1995), cheating during examination is an assault upon the basic integrity and meaning of a university. The reasons students engaged in academic dishonesty varied. In a study conducted by Jones (2011), the three most common responses indicate grades (92\%), procrastination (83\%) and being too busy, not having enough time to complete assignments or study for tests (75\%). In attempting to understand student cheating, Hutton (2006) concluded that students cheat because the cost/benefit trade off favours cheating, with a very low probability of being caught and rare reporting by faculty. Murdock and Anderman (2006) discovered that the opportunity to engage in destructive behaviours may include cheating in assignments and examinations, or plagiarising written works. For the purpose of this study, cheating in examinations is the central focus. These dishonest behaviours may results in high grades or "success", but the student would demonstrate that he or she was a "fraud" and not deserving of the high performance he or she obtained if caught (Ferrari, 2005).

Puka (2005) highlights that at most universities students are banished from their learning community for cheating and plagiarism. The unwitting lesson taught here is that enlightened and reflective communities handle rule violations and significant faults in their members by 'changing the locks on the doors'. If the student's offence is small, expulsion is replaced by 'hard labour', usually in the form of assigned research on academic honesty (Puka, 2005).

\subsection{Cheating and distance learning}

Distance learning is the process whereby the education of a student occurs in circumstances where the educator and the student are geographically separated, and the communication across this distance is accomplished by one or more forms of technology (....). Moore and Kearsley (1996) describe the distance learner as someone: between the ages of 25 - 50; slightly more likely to be female; probably married; probably employed fulltime; and studying for the purpose of a better job. Given this information, distance learning students lack direct interaction with their instructors. As the two are separated by time and space, students might experience a feeling of isolation as well as perceptions of inaccessibility and distance and this situation offers a unique venue for academic dishonesty (Kennedy, Nowak, Raghumaran, Thomas and Davis, 2000). Kelly and Bonner (2005) suggested that students who feel close to their professors tend to be more honest. Students who feel distant from others are more likely to engage in deceptive behaviours, such as cheating (Burgoon, Stoner, Bonito, and Dunbar, 2003).

There seems to be a widely - held belief that cheating is easier in distance learning classes. According to Kennedy et al (2000), as the number of distance learners increase, so is academic dishonesty. In their survey of student and faculty views concerning cheating and distance learning, Kennedy et al (2000) indicate that $64 \%$ of faculty and $57 \%$ of students reported that it would be easier to cheat online than face-to-face distance learning classes. Cheating was much more prevalent in online classes compared to traditional lecture courses (Lanier, 2006).

In contrast, Harmon, Lambrinos and Buffolino (2010) found that 50\% of students reported the frequency of 
cheating online as the same as face-to-face. Academic dishonesty occurs frequently and equally in online and face-toface courses (Dietz-Uhler and Hurn, 2011). Other studies (Struber-McEwen, Wiseley and Hoggatt, 2009) found that cheating was more prevalent in traditional than online courses. Stephens, Young and Calabrese (2007) found that conventional cheating is more prevalent than digital forms of cheating.

\subsection{Cheating in the South African context}

South African universities and technikons view cheating as a growing problem, and they have vowed to take a zerotolerance stand (Sunday Times, 7 March 2004). Some universities in South Africa are now circulating the names of cheats to other institutions, employing 'copyright officers' and even looking at buying software that weed out copyright infringers. For example, Sunday Times (7 March 2004) reveals that at the University of the Witwatersrand the problem was particularly common among first-year students because intellectual property and cheating were not adequately addressed at high school. The University of KwaZulu-Natal started publishing the names of cheats and plagiarists on campus notice boards. University of Zululand students found guilty of cheating or plagiarising were automatically suspended for two years and other universities were alerted to keep an eye on those students should they decide to enrol at other universities. The University of Cape Town considered plagiarism to be such a serious offence that it required students to sign a declaration on every assignment stating that 'plagiarism is wrong', that the work handed in is the student's own and that of others has been adequately referenced and attributed.

\section{Methodology}

This article is based on a case study conducted in one of the distance learning universities of South Africa. The aim was to describe the students' reasons of engaging in cheating behaviour during the examinations (Greenhalgh and Taylor, 1990). A qualitative case study design was employed in this study to collect and analyse data. Case studies are detailed, concrete and specific studies of particular situations; they are about 'what really happens' (Rule and John, 2011). The students under investigation in this study, are those that enrolled for the undergraduate qualification, the Advanced Certificate in Education (ACE). This qualification offers eight specialisation programmes that students may select from. In each of the programmes, there are five courses that students have to complete in order to receive their qualification. Assessment in this qualification is carried in two ways, i.e. formative and summative assessment. Formative assessment is done through the completion of written assignments. Summative assessment may take either a formal examination or submission of a portfolio of evidence. For the purpose of this study formal examination is the central focus in this article. In this assessment, all the registered students who qualify to write the examination are provided with a timetable indicating the course, examination venue and time for the examination. This suggests that for every course, examinations are written at the same time at various examination venues.

\subsection{Sources of data}

Data was gathered through the primary sources requested from the organization under investigation. These sources were specifically documents that recorded the disciplinary procedures in the form of minutes compiled by the student disciplinary department. In these documents, 29 cases which were discussed during the disciplinary hearing were recorded. The cases involve all the students that were caught cheating during the 2011 examinations. The documents under discussion in this study include the invigilators' observation records during examinations, records of individual student interview during disciplinary hearings, records of students' written statements after the conclusion of the examination, copies of second examination scripts after unauthorised materials were confiscated; evidence of unauthorised materials used by students during examination; and the examiners' reports. The selection of documents were based on their availability, with no cost and with the view that they would shed light on the phenomenon under investigation (Cohen, Manion and Morrison, 2005; Maree, 2011). These documents assisted in uncovering meaning, developing understanding and discovering insights relevant to the research problem (Merriam, 1988), as well as providing a rich amount of analytic topics and a valuable source of information (Hammersley and Atkinson, 1995).

\subsection{Data analysis}

Case study research is not limited to a single source of data (Yin, 2012), they offer a multiple-perspective analysis in which not just the voice and perspective of one or two participants are considered in a situation, but also the views of 
other relevant groups of actors and the interaction between them (Maree 2011). In light of the above, content analysis was employed in this study to analyse all the reports as mentioned in the sources of data section above. Content analysis is an inductive and interactive process where similarities and differences in text that would corroborate or disconfirm theory are looked for (Maree 2007).

\subsection{Ethics}

Ethical procedures in line with the institution's policy were followed to access the records where disciplinary procedures were recorded. These include the promise to ensure autonomy and beneficence as outlined by Rule and John (2011). In the entire article, there is no mention of either the names of people involved in the study or the student numbers of students involved. To ensure trustworthiness of the study the findings were sent to the student disciplinary matter to check the interpretations of data and the conclusion of the study (Rule and John, 2011).

\section{Findings}

The objective of the study was to present an overview of students' reasons for engaging in cheating behaviour during examinations. The findings of this study are classified and discussed under the mentioned categories.

\subsection{Lack of time for exam preparations}

Upon investigation of the causes of student cheating, it is indicated in the study that students lack time to prepare themselves for the examinations. Lack of time may be caused by unhealthy conditions of either a family member or the student him or herself. It is a fact that when someone is not healthy, there would be no thorough work done. Even a sick person him or herself cannot perform his or her duties accordingly. This will cause a sick person to focus more on his or her health conditions. In view of the above, candidates in this study were found to be experiencing unhealthy conditions. One of the candidates reports her or his reasons: "The lady found the small paper in my answer sheet and apologized for that cheating. It is because of I am sick and I cannot concentrate while I am studying. That small paper does not have the information. I did not use it."

In case of a family member who is sick, the person who takes care of the patient contributes lot of his or her time to the patient. It is evident in this study that one of the candidates became involved in this situation, the candidate reports his or her views in this way: "I would like to state l've been caught copying. The reason is I did not have enough time to study because my mother is very ill, she is seriously ill and she has been diagnosed with a lump in the lower abdomen. She is already admitted at King Edward for an operation. I was up and down trying to solve her problem that is all I want to state. I'm very sorry and disappointed due to this. In case of I fail this subject please grant me with a supplementary and allow me to study further."

\subsection{Family bereavement}

It is evident from the findings that candidates experience some emotional disturbances due to family bereavement of the parents, siblings or spouses. One of the candidates who experienced the similar situation explains his or her circumstances as follows: "It's because I have a problem of my mother she is dead, so I did not read my books." These bereavements do not only affect emotional conditions of the candidates, they also affect their health conditions. One of the candidates who claim to have been affected by this bereavement states: "I'm very ill today and my mother died at night. I'm really sorry. I did not have intentions, please forgive me. My sugar (diabetic) is up." family bereavement is also a contributory factor to depression or stress which students cannot cope with during the examinations. In this study, it was found that one of the students suffered stress from family bereavement and she or he report the situations as follows: "I was stressed because my father died on 24/10/11. Sorry for doing this, I have no time to read because of the stress that I have."

\subsection{Forgetfulness}

Due to stress and depression some students experience loss of memory and forget easily. This means that they cannot recall or link what they read about. One of the students who experienced this situation explains: "I was having stress since I lost my spouse, I did read hard for the exam but the problem I have in the child rearing style, I forgot one and I 
have tried to remind it and the invigilator see me and she take my paper and give me the other one and then I have continued to write for myself." Another student who also suffered forgetfulness reports her reasons in this way: "I would like to apologize, I'm awfully sorry for what I did. I made a silly mistake by having a piece of paper for a reminder during exam when writing. I tried to study but due to my illness I easily forget. Last month I was hospitalized at Entabeni Hospital having major stress. I am so disturbed at home as I'm undergoing this depression. Sorry for my mistake, unfortunately I was about to use that paper and the lady caught me while I was trying to place it under my question paper."

\subsection{Family responsibility}

Some family responsibilities during examinations may also contribute to poor student preparation. This will of course force the student to lose focus on his or her studies. Family responsibilities such as weddings need some thorough preparations that will consume the students' study time. One of the candidates who was involved in the wedding preparation gave the following explanation: "I have done the bad thing of having notes during the examination period. It's because I did not have a chance of reading because of the incident of my daughter who was getting married now at my in-laws' home. I was busy doing preparations for her because my husband told me to do all the preparations for our daughter. These preparations make me not to get the chance of reading and I'm not happy of my daughter who was married because there are lot of things I want from her, she is my first born. There is nothing she does for me. Last year she was graduating her diploma and got work this year. But she got married that makes me to be so disappointed. After that I was admitted by doctor and have two drips at doctor's surgery."

\section{Discussion}

Based on the data analysis, it is evident from this study that students are engaged in the cheating behaviour during examinations. The findings of this study are in line with Norton et al, as well as Rettinger and Kramer. In their study Norton et al (2001) determined that half of all college students engaged in academic dishonesty in assessment settings. Rettinger and Kramer (2008) on the same note highlights that $73,4 \%$ reported engaging in at least one of the cheating behaviour, and 37, 7\% reported serious cheating on an examination. The reasons students engaged in academic dishonesty varied. Students in this study mentioned lack of time as contributory to their engagement in academic cheating. It is evident in this study that most of the study time was assigned to health problems experienced by either the students themselves or their family members. This finding is corroborated by Jones (2011) who indicated that $75 \%$ of students cheat because of being too busy, not having enough time to complete assignments or study for tests. Family bereavement also contributed to academic cheating as students could not concentrate on their studies. Other reasons for cheating include forgetfulness whereby students used unauthorised notes as a way of reminding themselves some of the facts in their course content. Family responsibilities also play a major role as a factor contributory to cheating. Students in this regard could not strike a balance between family responsibilities and study time. For them to achieve, they decided to cheat. As this behaviour is practiced by students in distance learning, this may suggest that the time and distance between the students and institution influenced students to be engaged in the cheating behaviour. This finding is corroborated by Kennedy et al, Burgoon et al, Kelly and Bonner. According to Kennedy et al (2000), students might experience a feeling of isolation as well as perceptions of inaccessibility and distance and this situation offers a unique venue for academic dishonesty. Students who feel distant from others are more likely to engage in deceptive behaviours, such as cheating (Burgoon et al., 2003). Kelly and Bonner (2005) suggested that students who feel close to their professors tend to be more honest.

\section{Conclusions and Recommendations}

The objective of the study was to present an overview of students' reasons for engaging in cheating behaviour during summative assessment (examinations). The findings revealed that students cheat because of lack of time for exam preparations, family bereavement, family responsibilities and forgetfulness. Data from the documents showed that students are involved in cheating during examinations despite the fact that they are provided with copies of the university's ethical policies prior to registration. Despite the adoption of academic honesty policies and the completion of academic integrity tutorials prior to registration, students are still involved in cheating behaviour during examinations. The study population includes the undergraduate students who registered the ACE qualification in a distance learning institution of higher education in South Africa. The study has some limitations. Firstly, a single data collection method (document analysis) was considered for the study. Students appeared in disciplinary hearing and to protect them from 
psychological harm, it was not possible for the researcher to interview them. Individual interviews would have provided richer data if practically and personally conducted by the researcher. Secondly, the study did not draw data from the entire university. It only focused on one of the faculties of the institution under investigation. Lastly, the sample size of twenty-nine is too small to be generalised to the entire institution. In conclusion, the theory of planned behaviour (Ajzen, 2006) became relevant to this study as students had intentions to cheat (control beliefs), as such they planned the behaviour before getting to the examination and applied it (normative beliefs. It was unfortunate that they were caught and could not reach their objectives (behavioural beliefs). According to Ajzen (2006) given a sufficient degree of actual control over the behaviour, people are expected to carry out their intentions when the opportunity arises. Despite personal reasons given by students for their engagement or attempt to cheat, to maintain the integrity of the institution, disciplinary code of ethics has to be respected and implemented by all the stakeholders. There is no evidence that students read and understand the contents of the policies given to them. Recommendations in this study therefore emphasised that ethical policies should not only be given to students; they have to be explained to them so as to understand the contents of the policy, that is, rules and disciplinary measures. It is hoped that this article will trigger the college management, teaching staff and students to reflect on how they may design orientation strategies that will assist in addressing the phenomenon of cheating in their disciplines.

\section{References}

Norton, L., Tilley, A., Newstead, S., \& Franklyn-Stokes, A. (2001). The pressure of assessment in undergraduate courses and their effect on student behaviours. Assessment and Evaluation in Higher Education, 26(3), 269-284.

Burgoon, J., Stoner, M., Bonita, J., \& Dunbar, N. (2003). Trust and deception in mediated communication. $36^{\text {th }}$ Hawaii International Conference on Systems Sciences, 44a.

Kennedy, K., Nowak, S., Raghuraman, R., Thomas, J., \& Davis, S.F. (2000). Academic dishonesty and distance learning: Student and faculty views. College Student Journal, 34(2), 309-314.

Callahan, D. (2004). The cheating culture. Why more Americans are doing wrong to get ahead. Orlando, FL: Hartcourt.

Cohen, L., Manion, L., \& Morrison, K. (2005). Research methods in education. London: Routledge Falmer.

Ferrari, J. R. (2005). Impostor tendencies and academic dishonesty: do they cheat their way to success? Social Behaviour and Personality, 33(1), 11-18.

Greenhalgh, T., \& Taylor, R. (1990). How to read a paper: papers that go beyond numbers (qualitative research). London: Macmillan.

Hammersley, M., \& Atkinson, P. (1995). Ethnography Principles in Practice. London, Routledge.

Hagstrom, F. (2006). Formative Learning and Assessment. Communication Disorders Quarterly, 28(1), 24-62.

Hutton, P.A. (2006). Understanding student cheating and what educators can do about it. College Teaching, 54(1), 171-176.

Jones, D.L.R. (2011). Academic Dishonesty: Are More Students Cheating? Business Communication Quarterly, 74(2), 141-150.

Lambert, E.G., Hogan, N, L., \& Barton, S.M. (2003). Collegiate Academic Dishonesty Revisited: What Have They Done, How Often Have They Done It, Who Does It, And Why Did They Do It? Electronic Journals of Sociology.

Maree, K. (2007). First steps in research. Pretoria: Van Schaik.

Merriam, S.B. (1988). Case study research in education: a qualitative approach. London: Jossy Bass Publishers.

Murdock, T.B., \& Anderman, E.M. (2006). Motivational Perspectives on Student Cheating: Toward an Integrated Model of Academic Dishonesty. Educational Psychologist, 41(3), 129-145.

Nelson, H. (1995). The academic dishonesty. Retrieved on 23/09/2012 from http://hep.ucsb.edu/people/hnn/conduct/disq.html.

Puka, B. (2005). Student Cheating. Liberal Education Summer/Fall 2005.

Rule, P., \& John, V. (2011). Your guide to case study research. Pretoria: Van Schaik.

Sunday Times. (2004, March 7). SA Media - The University of the Free State. Ref No. 1216, ID 0305 7301-01.

Teixeira, A.C. (2008). Measuring aggregate human capital in Portugal: 1960-2001. Portuguese Journal of Social Science, 4(2), 323-342.

Trost, K. (2009). Psst, have you ever cheated? A study of academic dishonesty in Sweden. Assessment \& Evaluation in Higher Education. 34(4), 367-376.

Wotring, K.E., \& Bol, L. (2011). Generational Differences among Community College Students in their Evaluation of Academic Cheating. Community College Journal of Research and Practice, 35(9), 724-735.

Yin, R.K. (2012). Applications of Case Study Research (3rd Ed.). Thousand Oaks CA: SAGE.

Rettinger, D.A., \& Kramer, Y. (2008). Situational and Personal Causes of Student Cheating. Res High Educ, 50: 293-313.

Robinson, C.V. (2013). Academic Dishonesty: A guide for Digital Instructors. In M.S. Plakhotnik \& S.M. Nielsen (Eds.), Proceedings of the $12^{\text {th }}$ Annual South Florida Education Research Conference (pp. 189-194).

King, C.G., Gugette, R.W., \& Piotrowski, C. (2009). Online exams and cheating: An empirical analysis of business students' view. The Journal of Educators' Online, 6(1), 1-11.

Struber-McEwen, D., Wiseley, P., \& Hoggatt, S. (2009). Point, Click, and Cheat: Frequency and Type of Academic Dishonesty in the Virtual Classroom. Online Journal of Distance Learning Administration, XII (III). 